\title{
Fronteiras materiais e espirituais: exibindo a coexistência entre deus e outros parentes afro-caribenhos em Old Bank, Panamá ${ }^{1}$
}

\author{
Claudia Fioretti Bonglanino
}

\section{Exibindo os nain nait}

Narrativas e experiências relacionadas aos familiares (vivos e mortos), espíritos e bruxaria interagem com duas doutrinas cristãs diferentes em Old Bank. Nesse vilarejo insular, situado na costa atlântica do Panamá2, estão presentes há mais de um século, seja a Igreja Metodista, seja a Igreja Adventista. A interação histórica entre essas doutrinas distintas e também entre outras narrativas e práticas é

1 Esse trabalho se baseia em pesquisa realizada com apoio do Conselho Nacional de Desenvolvimento Científico e Tecnológico (CNPq - Brasil) e do Programa de Pós-Graduação em Antropologia Social do Museu Nacional da Universidade Federal do Rio de Janeiro (PPGAS/MN/UFRJ).

2 Old Bank se situa na região panamenha de Bocas del Toro, que é delimitada por um trecho continental no nordeste do país, próximo à fronteira com a Costa Rica (a cerca de $30 \mathrm{Km}$ de distância), e pelo arquipélago adjacente homônimo composto por nove ilhas, além de 250 ilhotas não povoadas. A região de Bocas del Toro abriga pouco mais de 3\% da população do país (125 mil de 4 milhões de pessoas) e tem cerca de $5 \%$ de sua área $\left(4.500 \mathrm{~km}^{2}\right.$ de $\left.75.500 \mathrm{~km}^{2}\right)$, apresentando uma variação demográfica análoga à nacional: cerca de $14 \%$ da população de Bocas del Toro se identifica como afro-panamenha, 17\% como indígena, $5 \%$ como chinês-panamenha, $8 \%$ como branca (estrangeira) e 56\% como latino-panamenha (latina), em comparação ao total nacional com 16\% de negros, 12\% de indígenas, 3\% de chineses-panamenhos, $11 \%$ de brancos estrangeiros e 58\% de hispânicos. As Ilhas Colón e Bastimentos eram as principais da região de Bocas del Toro, hospedando as duas vilas maiores, respectivamente a capital e Old Bank. Esta vila era chamada, em espanhol - idioma oficial do país -, de Bastimentos pelas autoridades nacionais e descrita como uma localidade de 1,3 $\mathrm{Km}^{2}, 738$ habitantes e 193 casas (INEC 2009-2010). Em 2015, segundo levantamento informal que realizei, Old Bank contava com 200 casas e 1200 habitantes, cuja principal ocupação era o serviço turístico (empregados em pequenos restaurantes e pousadas turísticas de iniciativa estrangeira ou local). Incrustada na ponta noroeste da ilha de Bastimentos, Old Bank se voltava, a oeste, para as fortes ondas do oceano Atlântico e, ao sul, para as águas tranquilas da baía de Almirante. À vila, se chegava apenas de barco (em um deslocamento de quinze minutos), após o percurso de uma hora de avião desde a capital do Panamá ou da Costa Rica para a capital da região. Outra opção era enfrentar as doze horas de ônibus desde as capitais de um dos dois países até o porto de Almirante, no continente e, em seguida, seguir de barco, primeiro por trinta minutos, até a capital da região e, finalmente, por mais 15 minutos, até a vila. Vale frisar que, diferentemente da região como um todo, a vila de Old Bank não correspondia propriamente a um microcosmo da diversidade nacional. Era, sim, a única vila panamenha cuja maior parte da população (95\%) se identificava como afro-caribenha, declarava-se protestante e preservava o guari-guari como primeiro idioma, embora também falasse fluentemente espanhol e, com frequência, inglês. 
fortemente experienciada e expressa pelos habitantes locais durante a sequência de (ao menos) três encontros fúnebres simultaneamente familiares e religiosos que eram denominadas de nove noites - ou nain nait, no idioma nativo, o guari-guari ${ }^{3}$. Descritos como "tradição da nossa comunidade" (acóstium fi ui comiuniti), esses encontros começam com a vigília do setop na primeira noite e terminam com a vigília do nain nait, na nona, sendo a cerimônia diurna do funeral realizada em uma data intermediária. É importante frisar que todos eles giram em torno do canto de hinos, guiados por "irmãs da igreja" (sistá fam di church), mulheres cristãs afro-descentes, que os selecionam a partir do livro localmente chamado de Sanky. Outros atos centrais durante os nain nait são a distribuição de comida, o consumo de álcool, a enunciação de orações para deus ${ }^{4}$ e a atualização de práticas descritas como "só superstições nas quais não acreditamos" (ongl supersticion ui no biliv) - por exemplo, deixar intocados os pertences do morto.

Ao utilizar os termos "tradição" e "comunidade" para descrever esses encontros fúnebres, meus interlocutores não somente enfatizavam a importância dos nain nait, mas reconheciam explicitamente a centralidade que esses encontros fúnebres tinham na criação do coletivo em Old Bank. Isso também era frisado em três ações específicas que dirigiram a mim. Primeiro, informaram-me sobre os nain nait, pressupondo que tal tradição seria do interesse de uma antropóloga. Segundo, estimularam-me a participar deles, explicando-me que, caso desejasse ir, eu e qualquer outra pessoa seria bem vinda nesses encontros. Terceiro, eles desenvolveram, junto comigo, uma exposição sobre os nain nait, como parte de um museu sobre a história e a cultura da comunidade.

O museu foi idealizado pelo Sr. Ashburn Dixon, um habitante da vila que então ocupava o cargo político panamenho de representante (análogo ao de vereador no Brasil). O projeto ainda está em fase inicial, mas em 2016, participei de quatro reuniões de planejamento com a junta encarregada da elaboração do Plano Museológico, formada pelo político e por especialistas locais e estrangeiros. Depois dessas reuniões, a junta encaminhou o Plano para o governo nacional do Panamá e está atualmente aguardando o parecer oficial sobre a proposta.

Ao coletar narrativas, ajudar a projetar uma exibição museológica sobre os encontros fúnebres de Old Bank e participar deles, desenvolvi um interesse crescente pelos nain nait. Tal interesse estava relacionado menos à habilidade que os nain nait tinham de produzir uma forte experiência coletiva para a população local e mais às seguintes perguntas: quais agências (não/humanas i/materiais) participavam

3 O guari-guari (ou gwar-gwari/wari wari) é localmente chamado também de patuá ou inglês, sendo caracterizado por uma informalidade análoga a de outras variantes do inglês nas Américas e Caribe, que não apresentam uma forma padrão (ortodoxa, por assim dizer) oral ou escrita, levando a maioria de seus analistas a adotar uma abordagem fonética informal ao transcrevê-los. Seguindo essa mesma abordagem, transcrevo foneticamente as citações no idioma local, preferindo essa expressão ao nome guari-guari, posto que ele é considerado derrogatório por várias das pessoas nativas de Old Bank. Utilizando um padrão desenvolvido por minha professora do idioma local, emprego o alfabeto espanhol para reportar os sons das vogais e o alfabeto inglês para os sons das consoantes. Cabem aqui, porém, algumas apreciações linguísticas. Denominado pela literatura especializada de Panamanian Creole English, ou Crioulo Inglês Panamenho (CIP), o idioma local corresponde a um crioulo que (como o nome técnico informa) deriva do Inglês e é falado por 8\% da população do Panamá (Snow 2007) e 96\% da população de Old Bank. Trata-se da língua materna de aproximadamente 100.000 afro-descendentes que residem nas regiôes da Cidade do Panamá, de Colón e de Bocas del Toro, havendo uma ou mais variantes de CPI em cada região (Reid, $\mathrm{H}$. 2013). O CIP e suas variantes foram insuficientemente documentados e analisados (Spragg 1973; Justavino, 1975; 2010; Brereton 1992; Aceto 1995a; 1995b; 1996; 1998; Snow 2000; 2001; 2003; 2004; 2005; Reid, H., 2013), mas foram abundantemente mencionados em estudos comparativos (Muehleisen e Migge 2005; Schneider e Kortmann 2004).

4 Optei por grafar em letra minúscula os termos 'deus' e 'diabo' - que formalmente são escritos em maiúscula - para evitar que eles sejam associados de maneira automática a seus homônimos cristãos, ou seja, Deus e o Diabo. Para maiores informações sobre as implicações etnográficas e analíticas dessa escolha, ver: Bongianino (2018). 
da experiência coletiva forjada pelos nain nait? Quais eram as fronteiras entre os nain nait, enquanto ritos extra-ordinários, e os atos de cuidado ordinários relacionados à vila familiar e às práticas sagradas, localmente englobados todos no termo "tradição"?

\section{"Mas é só nossa tradição"}

Essas perguntas surgiram como questões centrais durante meu trabalho de campo em função da recorrência de comentários como o que ouvi de Kayra, uma das mulheres que conduzia o canto do Sanky:

É importante ir aos nain nait para solidarizar-se com a família. Aqui em Old Bank, todos fazemos os nain nait quando temos um morto só que nem todos participamos dos nain nait dos outros. Muita gente diz que tem muita superstição. [...] Mas é só nossa tradição. [...] Se estamos com deus não temos nada a temer.

Comentários como esse sugeriam uma aparente incongruência a respeito dos nain nait e do conceito local de tradição, os quais pareciam ser ao mesmo tempo valorizados e desvalorizados. Com efeito, o uso da conjunção adversativa 'mas' e do advérbio 'só' sugeria a existência de uma hierarquização entre deus e a 'nossa tradição', relegando esta ao segundo plano, ou seja, a um lugar menor, talvez a uma religião tradicional de matriz africana, aparentemente restrita ao passado e desprovida de importância. Essa impressão prévia caia por terra, porém, ao atentar para outros usos do conceito de tradição, para além dos nain nait.

“Todos dizemos deus primeiro quando falamos sobre algo que vamos fazer, mas é só nossa tradição. [...] Aqui todos acreditamos em deus, vamos ao culto e mandamos as crianças para a igreja, mas é só nossa tradição". Essas palavras de minha professora do idioma local, Soly, rompiam com a hierarquia, por mim vista até então, entre deus e tradição, pois incluíam nesta última práticas vinculadas ao sagrado. Tais práticas implicavam uma aproximação a deus e às igrejas cristãs, ainda que não correspondessem a uma filiação religiosa formal. Por esse motivo, em vez de englobá-las em rubricas analíticas como cristianismo ou religião, preferi denominá-las de gestos cristãos cotidianos, expressos, por exemplo, nas seguintes ações: citar expressões como 'deus primeiro'; expressar sua crença em deus; ir ao culto; mandar as crianças para a igreja; entre outras.

Semelhantemente, fui surpreendida com o comentário de um amigo de aproximadamente 40 anos que não tinha o hábito de ir a nenhuma igreja. Conversávamos sobre meus interesses de pesquisa, entre os quais tinha passado a incluir 'a importância de deus para a vila', quando ele me corrigiu:

Não, deus não é importante (impuórtant) aqui na vila. Talvez para as pessoas de antigamente deus fosse importante, mas não hoje (tudie). Pelo menos não para os jovens, como você e eu. Aqui as pessoas só se lembram de deus quando estão perto de morrer ou quando têm um problema. Aí todo mundo se lembra dele - inclusive eu mesmo, não posso negar. A verdade é que aqui todos acreditamos em deus, mas não nos lembramos dele. Só nos lembramos de deus quando temos um problema (gat a problema). Nessas horas, todo mundo conversa (tálk) com deus em oração (preiá), 
procura por respostas (ansá) lendo a Bíblia e se lembra (remembá) de que ele é importante. Mas só nessas horas.

Tendo começado sua fala negando enfaticamente a importância de deus, ele concluiu seu argumento confirmando-a com veemência, ainda que a restringisse aos momentos em que as pessoas tinham um problema (gat a problema). E a morte parecia ser o problema por excelência em que deus era lembrado. De fato, todo falecimento (mesmo de quem residia fora da vila) era anunciado publicamente pelo badalar inesperado do sino da Igreja Metodista, a qual correspondia, junto com a Igreja Adventista, às duas únicas instituições religiosas dotadas de uma sede de culto nessa vila afro-caribenha - onde a maior parte da população (95\%) descendia de trabalhadores livres que chegaram do Caribe inglês entre os séculos XIX e XX.

Em Old Bank, assim que era confirmada uma morte, a família ligava para o rapaz encarregado de tocar o sino ou pedia que alguém fosse até a sua casa, avisar do ocorrido. No meio tempo, o corpo do morto era levado para o necrotério, onde permanecia até o fiuneral, isto é, a cerimônia fúnebre e o enterro, enquanto as vigílias noturnas do setop e nain nait eram realizadas sem a presença dele. Então, a família comunicava o ocorrido, pessoalmente ou por telefone, aos parentes, amigos e vizinhos mais íntimos que viviam na vila ou que tinham migrado para outra localidade. Todas essas pessoas mais próximas compartilhavam com a família a dor da perda e alguns ajudavam-na nas tarefas e na manutenção dos custos envolvidos na organização dos nain nait. Organizavam na casa familiar (fámili huôm) ${ }^{5}$ as vigílias do setop e do nain nait, preparando a comida e a bebida (principalmente o rum e a cerveja) que seriam servidas às visitas que permaneciam a noite toda na sala com as 'irmãs da igreja', cantando músicas cristãs, ou no quintal, conversando e jogando dominó e baralho. No meio tempo, planejavam o funeral a ser celebrado em uma das duas igrejas locais, posteriormente no cemitério e culminava em farta distribuição de comida na casa familiar.

O entrelaçamento produzido pelos nain nait entre vida familiar, funerais e as igrejas cristãs locais indicavam que os nain nait, as 'superstições' vinculadas a elas e os gestos cristãos cotidianos pertenciam ao mesmo campo semântico do conceito nativo 'nossa tradição'. Tal fato, conquanto não fosse surpreendente em si mesmo, indicava as distintas e simultâneas tensões que permeavam a noção de tradição. Direta ou indiretamente, os argumentos acionados em relação a ela seguiam sempre as mesmas estruturas, marcadas pelas ponderações 'mas é só' ou 'mas não' (bat dé ongl): de um lado, 'todos repetimos superstições, mas é só nossa tradição', 'todos fazemos nain nait, mas é só nossa tradição', 'todos acreditamos em deus, mas é só nossa tradição'; de outro, 'todos repetimos superstições, mas não acreditamos nelas,' 'todos fazemos nain nait, mas não participamos deles', 'todos acreditamos em deus, mas não nos lembramos dele'.

5 Casa familiar (fámili huôm) era o termo localmente utilizado para se referir à residência da infância, isto é, à casa em que ego viveu quando criança junto com a mãe e/ou a avó (materna ou paterna). Localizada na terra familiar (fámili lánd), essa casa era mantida como posse coletiva para que fossem ocupadas pelos familiares que precisassem e corresponde a um elemento central nas práticas e concepções de parentesco e religião em Old Bank (cf. Bongianino 2018). Para mais informações sobre a importância da casa familiar e da terra familiar em contextos afro-caribenhos, ver: Clarke (1999 [1957]), Mintz (1974), Besson (1984; 2002), Trouillot (1992); Olwig (1999; 2007), Carnegie (1987), Crichlow (1994) e Bongianino (2012; 2014). 
Havia, ainda, outra dimensão marcada por ponderações semelhantes àquelas que caracterizavam o conceito 'nossa tradição': a família. Em Old Bank era recorrente ouvir as pessoas (como Soly, Kayra e Ashburn) dizerem: “Todos somos família, mas não vivemos como família (ui dé al fámili, bót ui no liv al láik famili)". De fato, a maioria dos habitantes (95\%) traçava sua descendência a partir dos mesmos cinco antepassados fundadores. Eles correspondiam aos parentes ascendentes (patrilineares ou matrilineares) mais distantes acerca dos quais as pessoas da vila tinham conhecimento e todos esses antepassados fundadores vinham do Caribe, eram negros e protestantes. $\mathrm{O}$ vínculo com esses antepassados fundadores era precisamente o argumento acionado por meus interlocutores para explicar sua autoidentificação como afro-caribenhos, bem como a afirmação de que 'somos todos família' (ui al défámili).

Embora o conceito de tradição não fosse explicitamente acionado em relação à família, a frase 'todos somos família, mas não vivemos como família' lançava mão da mesma estrutura argumentativa discutida até aqui, podendo ser parafraseada da seguinte maneira: 'todos somos família, mas é só tradição'. Indiretamente, portanto, a família também pertencia ao mesmo campo semântico dos funerais e do cristianismo, daí a existência de tensões análogas. O presente texto se debruça precisamente sobre as tensões vinculadas aos nain nait, ao cristianismo e à família, mostrando como agências humanas e não-humanas, materiais e imateriais (como livros cristãos, álcool, deus e espíritos) eram constantemente mobilizadas em controvérsias vinculadas aos nain nait e a atos de cuidado ordinários relacionados à vila familiar e à práticas sagradas. Nesse sentido, as seções abaixo se debruçam sobre essas três dimensões da vida local (funerais, religião e parentesco), investigando sua relação os conceitos locais de tradição e herança.

\section{Funerais e herança em Old Bank}

Durante os 14 meses em que realizei trabalho de campo em Old Bank, entre os anos de $2013 \mathrm{e}$ 2017, etnografei 20 falecimentos $^{6}$ e realizei 11 entrevistas focadas nos nain nait. ${ }^{7}$ Uma das entrevistadas foi justamente Kayra, citada acima, que disse:

\footnotetext{
6 É importante explicar a razão do número alto de falecimentos que etnografei (20). Embora tenha feito pesquisa de campo durante 14 meses, pude incluir na análise mortes ocorridas enquanto não estava em Old Bank (de 2013 a 2017), porque mantive contato pela Internet com inúmeras pessoas. Além disso, dois desses falecimentos não ocorreram em Old Bank, pois os recém-falecidos não moravam lá. Contudo, ambos (um homem e uma mulher) haviam residido na vila no passado, onde ainda mantinham parentes e amigos. Estes viajaram para participar ao menos do fiuneral, celebrado, respectivamente, em Bocas Town e Manzanillo, na região costa-ricense de Limón. Inversamente, um dos nain nait foi sediado em Old Bank para um senhor que, conquanto não tivesse nascido na vila e, na época, já não vivesse nela, possuía uma 'família próxima' que residia no local. De todo modo, a taxa de mortalidade de Old Bank (17 falecimentos em 4 anos, totalizando uma média anual de 3,54\% falecimentos por 1000 habitantes) estava relacionada à precariedade do serviço público de saúde da vila. De fato, o posto de saúde local contava apenas com enfermeiras (e com um médico, uma vez por semana) que trabalhavam meio horário e o hospital mais próximo ficava na ilha vizinha (acessível após uma viagem de barco de 15 minutos).

7 As entrevistas foram conduzidas em Old Bank com dois homens (Ashburn Dixon e Lôlo Evans) e sete mulheres (Hanna Lewis, Nelva Lichel, Kayra Evans, Fita Evans, Soly Edwards, Deborah Evans e Vivy Gores). Também entrevistei duas mulheres de Bocas Town (Judith Jones e Carla Waker). Esses interlocutores foram selecionados por distintas razões. Alguns porque já conversavam espontaneamente comigo sobre os nain nait, outros porque tinham interesse e disponibilidade em responderem minhas perguntas. No caso de Hanna, Nelva e Kayra, porém, a escolha também estava relacionada ao fato de que elas eram as três "irmãs da igreja" que assumiam a responsabilidade de guiar o canto durante as vigílias fúnebres. Em Old Bank, eu falava com meus interlocutores em espanhol ou em inglês e eles me respondiam no idioma local. Faço notar que nenhuma de nossas interações foi registrada com uso de gravador. Algumas vezes tomava notas enquanto conversávamos, mas assim que voltava para casa as transcrevia sob forma de discurso direto, no diário de campo, e aproveitava novos encontros com os mesmos interlocutores para tirar eventuais dúvidas na transcrição. Vale ainda ressaltar que todos os nomes são fictícios (com exceção de Ashburn Dixon), conforme acordado com meus interlocutores, para garantir sua privacidade.
} 
Quando você tem um morto (gat a déd), cabe a você realizar os nain nait. [...] Quando a família não pode organizar os nain nait, a comunidade se une para ajudar ou até para fazer o setop, funeral e a nain nait para ela. E, mesmo quando a família próxima não precisa, os parentes, vizinhos e amigos ajudam-na do mesmo jeito. [...] Mas normalmente quem mais ajuda e assume a responsabilidade maior são as mulheres, porque elas cuidam mais, é da natureza delas.

'Ter um morto' (gát a déd, tener un muerto) era a maneira pela qual meus interlocutores se referiam à ocorrência de falecimentos. Eles não usavam a construção impessoal adotada por mim - ocorrência de falecimentos -, segundo a qual as mortes aconteciam, se abatiam etc. Quando falavam de uma morte específica, a formulação era pessoal e direta: "fulano morreu", sendo a pessoa ainda viva o sujeito da ação e sua morte, seu ato derradeiro. Já ao mencionarem falecimentos em geral, o sujeito da ação passava a ser outro, isto é, quem 'tinha o morto'. Tal fato, menos que sugerir uma ausência de agência ou personalidade própria ao recém-falecido, demonstrava que ele não era um morto qualquer; em vez disso, pertencia a determinadas pessoas, sendo por vezes utilizados também os possessivos 'meu morto' (mi déd) e suas variações 'teu/seu/nosso/vosso/s morto/s' (iô/him/shi/ui/uno déd) para lhe fazer alguma referência.

Como sublinhou Kayra, 'ter um morto' remetia ao fato de que a responsabilidade de realizar os nain nait era da 'família', precisamente da 'família próxima' (cluôs fámili). Essa categoria local englobava os parentes mais íntimos, mesmo os que residiam fora de Old Bank. Ou seja, estavam inclusos todos os parentes ascendentes, descendentes, laterais e afins diretos: pais, filhos, irmãos e, no caso de casais casados (leia-se, que viviam na mesma casa), também os cônjuges. No entanto, na vila, a categoria da 'família próxima', tal qual inúmeras outras vinculadas à noção de 'família', não apresentava uma definição rígida, tampouco determinava, de maneira exclusiva, quais pessoas estavam incluídas ou excluídas dela. Em sua fala, por exemplo, Kayra citou a 'família próxima’ e a 'família', utilizando as duas categorias como sinônimo e contrapondo-as a 'comunidade'. Este último termo era raramente acionado fora do contexto dos nain nait e, menos do que denotar um grupo maior que a família (formado, por exemplo, pela soma das famílias), era usado para apontar as pessoas que não eram da 'família próxima'.

Em outra entrevista, dessa vez com Hanna, percebi que a fórmula 'ter um morto' não denotava apenas os parentes íntimos. Listando, a meu pedido, os encontros fúnebres organizados para quem ela denominava de 'meu morto', minha amiga mencionou a morte de dois de seus filhos, de um irmão e também de seus pais. Em sua fala, chamava a ambos de 'o meu velhinho' e 'a minha velhinha' (mi viejito/a), lançando mão de uma terminologia de parentesco mais carinhosa, comumente usada por filhos em relação a seus ascendentes, normalmente pais e avós. Reparei, porém, que ela mencionara duas vezes a expressão 'o meu velhinho' e indaguei se havia sido um erro. Explicou-me, assim, que se tratava de

8 Em Old Bank, o termo 'família' era geralmente utilizado de maneira contrastiva, sendo a 'família próxima’ oposta à 'comunidade’ e também à 'família distante' ('distánt fámili'). Meus interlocutores utilizavam esta categoria ao discorrer sobre a proibição do incesto, como aprendi com uma professor da escola: "Aqui todos 'somos família.' Quando falamos isso aos estrangeiros, muitos se assustam porque casamos entre nós. Mas não casamos com quem é 'família próxima', só com quem é distante (distant). Por exemplo, se um Davies casar com um Davies, o filho será Davies Davies. Isso é mau! Só casamos com parentes distantes”. Agradeço à antropóloga Amanda Horta por ter me ajudado, em uma comunicação informal, a perceber esse uso contrastivo dos termos 'família [próxima]' e 'comunidade'. 
duas pessoas diferentes, seu pai e um vizinho, aos quais se referia por meio da mesma terminologia de parentesco. A esse respeito, Hanna detalhou:

\begin{abstract}
Meu velhinho e a esposa viviam em uma casa aqui em frente à minha. Sempre 'vivemos como família', gritávamos o nome um do outro, conversávamos (tálk), eles ficavam de olho nos meus filhos brincando no quintal. Depois que ficou viúvo, adoeceu e eu passei a cuidar dele. Por isso, fui eu que organizei os nain nait dele. Os filhos do meu velhinho viviam na Cidade do Panamá e ajudaram. Alguns vieram, outros mandaram dinheiro, como fez também o meu filho que mora nos Estados Unidos. Muitas pessoas ajudaram, além deles, mas eu que cuidei de tudo, porque quando você tem um morto, cabe a você fazer os nain nait.
\end{abstract}

Portanto, a locução 'ter um morto' também podia se remeter a alguém que não era, de antemão, 'família próxima' - e sim 'comunidade', seguindo o contraste mencionado acima. Nesse caso, o determinante para a realização dessa vinculação era o fato de que 'viviam como família', tal qual faziam Hanna e 'seu velhinho'. Ou seja, eles gritavam o nome um do outro e 'conversavam' (tálk). O vizinho cuidava dos filhos de Hanna; quando ele adoeceu, foi sua vez de cuidar dele. Por fim, quando faleceu, Hanna assumiu a responsabilidade de organizar seus nain nait.

A expressão 'viver como família' sinalizava a manutenção de relações harmoniosas entre as pessoas, ao partilharem a terra e os alimentos excedentes e, principalmente, ao evitarem os conflitos, brigas e rivalidades, o que, inversamente, caracterizava a convivência entre aqueles que 'não viviam como família'. Enquanto o segundo tipo de comportamento era descrito como negativo e evitado (inclusive por acarretar em riscos de bruxaria), as práticas englobadas no 'viver como família' pareciam corresponder a um padrão de relacionamento plenamente positivo. Nas palavras de Hanna, elas ganhavam ulterior concretude, podendo ser resumidas no verbo cuidar: ação que se direcionava aos mortos na realização dos nain nait e aos vivos, quando alguém se encarregava dos doentes, dos filhos e das pessoas em geral, partilhando alimentos e responsabilidades, evitando conflitos e comunicando-se com eles (ao gritar e conversar).

Sugiro denominar essas práticas de gestos familiares cotidianos, uma vez que correspondiam a atos determinantes na aproximação de pessoas, bem como na criação, na manutenção e no fortalecimento de vínculos que caracterizariam, em alguma medida, a família. Tais atos eram trocados diretamente (como nos gritos reciprocados por gritos), mas podiam ser voltados também para outrem e trocados indiretamente. Esse parecia ser o caso dos cuidados dirigidos aos filhos de Hanna por seu antigo vizinho, retribuídos por meio dos cuidados que ela lhe ofereceu durante sua doença e morte. Significativamente, esses atos apareciam como padrão de relacionamento cultivado não somente com as pessoas que eram consideradas 'família próxima', mas também com poucas daquelas que (por serem 'comunidade') se tornavam 'família próxima' ao 'viver como família'. Voltarei a esse ponto adiante.

Com as entrevistas sobre os nain nait, descobri que as músicas cristãs em torno das quais eles giravam eram selecionadas sempre a partir de um mesmo livro. Tratava-se de um hinário metodista usado exclusivamente nos nain nait, o qual fora impresso em Londres em 1890 e era localmente chamado de sanky - imagino em referência a seu autor, Ira Sankey -, embora se intitulasse Canções e Solos 
Sagrados (Sacred Songs and Solos). Somente quatro cópias desse livro ainda estavam disponíveis na vila, sendo resguardadas por três senhoras batizadas na Igreja Metodista.

Entre as três 'irmãs da igreja' que guiavam o canto do sanky, apenas Nelva não possuía uma cópia desse livro, do mesmo modo, somente ela era adventista. Não obstante, aprendera a cantar e guiar os hinos da mesma maneira que as outras 'irmãs da igreja' que o faziam. Aliás, como me contou, qualquer pessoa podia chegar a cumprir tal função de forma adequada: "Sempre amei (láv) cantar os hinos nos nain nait, por isso passava a noite toda na sala, ouvindo e repetindo os versos. Assim, aprendi os ritmos e tons da maioria dos hinos e comecei a conduzir".

Durante meu trabalho de campo, sempre as três mesmas 'irmãs da igreja' assumiram a responsabilidade de conduzir os hinos durante os nain nait, Kayra, Hanna e Nelva. Apesar desse padrão, não havia nenhuma exigência formal acerca dessa condução. Com fins meramente analíticos, optei por utilizar a denominação 'condutoras do sanky'. No entanto, saliento que essa posição social podia ser assumida de maneira informal, livre e autônoma por qualquer pessoa, isto é, sem que houvesse qualquer tipo de comissão. Não existia um ofício formalizado em torno da condução do sanky. Se tratava de um conhecimento oral, cujo aprendizado era condicionado apenas pelo amor e pelo fato de que quem desejasse adquiri-lo fosse capaz de identificar números e de ler um pouco em inglês - ao menos o suficiente para associar as letras cantadas àquelas escritas no sanky. De fato, números e palavras era tudo o que havia naquele hinário: os textos dos hinos eram numerados em ordem crescente, mas não eram acompanhados por partituras ou cifras.

Em função da informalidade que caracterizava a posição de condutora do sanky, não existia qualquer tipo de regra (nem mesmo tácita) que exigisse que apenas três pessoas a assumissem, tampouco que houvesse uma alternância entre aqueles que a realizassem. Não era preciso que as condutoras fossem mulheres nem que tivessem alguma idade específica ou que fossem batizados em alguma igreja. Segundo meus interlocutores, no passado, havia pessoas de variados perfis que assumiam esse papel durante os nain nait. É preciso destacar, ainda, que se podia prescindir das condutoras do sanky durante os encontros fúnebres e cantar ou tocar qualquer música cristã proveniente de discos ou da Internet'. Como me disseram, era assim que faziam na Cidade do Panamá, onde já não se tinha notícia de ninguém que possuísse uma cópia desse hinário. Por fim, era possível que, mesmo em Old Bank, outras pessoas assumissem temporariamente o papel de condutora do sanky.

Contudo, nenhuma dessas outras pessoas assumia a responsabilidade constante de guiar o canto, como faziam Kayra, Hanna e Nelva. O canto raramente começava sem uma das três, e embora outras pessoas o guiassem de maneira temporária e esporádica, somente as três se preocupavam em mantê-lo até o amanhecer, sem que nenhuma delas se sobrecarregasse nessa cansativa tarefa. Em tal contexto, não era mera coincidência que, no presente, as condutoras do canto fossem mulheres chamadas irmãs da igreja' e que tivessem sido justamente elas a herdar as únicas quatro cópias do sanky disponíveis em Old Bank - quiçá no Panamá, dado que já não se tinha notícias desse livro na capital do país. Tal fato

9 Faço notar que somente nas músicas cristãs tocadas a partir de CDs e da Internet o canto era acompanhado por instrumentos. Os hinos do sanky eram entoados à capela e o ritmo não era marcado por palmas (como as músicas cantadas nas igrejas). Também não eram usados tambores e as pessoas não dançavam. Já durante a cerimônia fúnebre na igreja e o cortejo até o cemitério, eram, por vezes, utilizados instrumentos musicais. 
mostrava como haviam assumido o controle dessa dimensão da vida local e sinalizava para a autoridade que detinham sobre ela. Sugeria, igualmente, que a razão pela qual herdaram o sanky era a mesma que as tornara condutoras do canto: $\mathrm{o}$ amor.

Embora esse sentimento partisse de um gosto e um desejo individual - o amor pelo canto -, ele se convertia em uma expressão de amor no sentido de cuidado, ou seja, uma ação coletiva espontânea, altruísta e, frequentemente, extenuante, isto é, guiar o canto dos presentes durante os nain nait realizados por todas as famílias locais em decorrência do falecimento de um ente querido. Portanto, ao desempenhar com assiduidade o papel de condutoras do sanky, Kayra, Hanna e Nelva demonstravam amor e cuidado não somente pelo canto, mas também pelos hinos cristãos, pelos nain nait e por todos os que estavam presentes neles: vivos, mortos, bruxos, deus e o diabo, como será desenvolvido abaixo. Mais que isso, elas evidenciavam que os amavam a ponto de se preocuparem e de assumirem a responsabilidade por eles.

Possivelmente, seus antepassados viram esse amor na prática durante os nain nait em que cantaram juntos e, por isso, tinham escolhido deixar especificamente para elas suas cópias do hinário. Havia ainda outras razões para explicar o motivo de terem sido elas as escolhidas para receber essa herança. De um ponto de vista religioso, elas eram batizadas nas igrejas cristãs locais e, assim, demonstravam que cuidavam de deus e daquilo que lhe dizia respeito - inclusive hinários, como o sanky. Já do ponto de vista familiar, a responsabilidade pela condução do sanky não era a única a ser assumida majoritariamente por mulheres. Elas estavam no comando da preparação da comida que seria distribuída e supervisionavam todos os preparativos dos nain nait, com a ajuda de outros parentes, vizinhos e amigos. Assim, elas assumiam esse papel central durante os encontros fúnebres como uma extensão do papel, também central, que tinham na criação e manutenção da família.

Em Old Bank, as mulheres eram as cuidadoras primárias de todos os parentes - algo comum em contextos afro-descendentes ${ }^{10}$. Isso começava com os fatos primordiais da gravidez, do parto e da amamentação, continuando no decorrer de toda a infância e idade adulta (em especial, no caso de parentes homens). As mulheres também assumiam a responsabilidade de cuidar dos parentes doentes, ao alimentá-los, medicá-los, levá-los ao médico e/ou rezar por eles. Para finalizar, quando um familiar morria, as mulheres organizavam os arranjos fúnebres - vigílias e fiuneral.

\section{"Todos fazemos nain nait, mas..."}

É importante organizar e participar dos nain nait para partilhar a dor da família, fazer companhia a ela, solidarizar-se. Nos nain nait você vê pessoas que não via há muito tempo... Algumas pessoas não participam dos nain nait, mas quando essas mesmas pessoas 'têm um morto' na família querem que todos estejam lá. É importante quando os amigos (frénd) e parentes vão e te dão apoio, ou mesmo quando não podem ir, porque vivem fora, mas fazem questão de te mandar uma mensagem. Nessas horas você sente que formam parte da sua família, porque elas se comportam como família, elas 'vivem como família' com você. Lembro que você foi nos nain nait da minha mãe

10 A centralidade feminina é um tema central na literatura sobre a família afro-descendente (cf. Bongianino 2014, 2015), classicamente analisado por meio do conceito de 'matrifocalidade' (R. Smith 1956). 
quando ela morreu. Lembro que a Carol também foi. Depois ela voltou para os Estados Unidos, mas sempre me lembro de que vocês duas estavam lá com a gente, cantando...

Quando entrevistei Kayra em 2016, no meu terceiro trabalho de campo, não esperava que ela falasse de mim ao discorrer sobre a importância de ir aos nain nait para 'solidarizar' (sympathize) com a família e partilhar a dor. Como ela e outros interlocutores frisaram, quando as pessoas faziam isso, "elas viviam como família com você”. Aprendi, assim, que participar dos encontros fúnebres era outro ato de cuidado englobado no 'viver como família', o qual se mostrava determinante para a aproximação entre as pessoas e para a criação, manutenção e fortalecimento de um vínculo de 'família próxima'. E estar ausente fisicamente não impedia essa participação, nem essa vinculação. De fato, os gestos familiares cotidianos incluíam também o solidarizar-se, o partilhar a dor e o envio de mensagens entre parentes e amigos, inclusive para os que estavam fora de Old Bank. Ademais, englobavam outras práticas análogas, como a distribuição dos custos e das tarefas entre quem residia, ou não, na vila - compra das bebidas, como refrigerante e cerveja, preparação da comida e empréstimo dos objetos necessários para os nain nait.

Todos esses gestos familiares cotidianos apareciam, pois, como um padrão de relacionamento que podia ser cultivado não somente com os residentes (fossem eles 'família próxima', fossem 'comunidade'), mas também com as pessoas ausentes (inclusive aquelas que eram descritas somente como 'amigas'). Entre esses cuidados estavam incluídos os gritos, as conversas, a atenção voltada para os momentos de doença e, sobretudo, de morte. Como ensinou o exemplo de Hanna e de 'seu velhinho', assumir a responsabilidade de organizar os nain nait era indício e sintoma de que ambos tinham um vínculo de 'família próxima'. Digo sintoma porque a escolha de assumir essa responsabilidade era motivada pelo fato de que ambos tinham esse vínculo. Entretanto, trata-se também de um indício, uma vez que essa escolha era percebida pelas demais pessoas como sendo motivada pela existência desse vínculo ainda que ele não necessariamente existisse e que outra razão motivasse a escolha, por exemplo, pena, interesse etc. Já no caso de Carol e eu (ambas estrangeiras temporariamente residentes em Old Bank), participar dos nain nait da mãe de Kayra - estando presente fisicamente, "lá com a gente, cantando" era indício e sintoma de que tínhamos com a falecida e sua filha um vínculo de 'família próxima', tendo sido nossa participação motivada por esse fato e sendo percebida como tal.

Ao recolher narrativas como as de Kayra e ao participar dos encontros fúnebres de Old Bank, deime conta da significativa habilidade que os nain nait tinham de aproximar as pessoas e de criar, manter e fortalecer os vínculos sociais por meio de gestos familiares cotidianos. Essa habilidade deles não era algo específico da vila. Desde o estudo fundador de Hertz (1907) sobre morte, assim como aqueles de Van Gennep (1960 [1909]), Durkheim (1989 [1912]), Mauss (2012 [1921]), Turner (1969), Fabian (1973) e outros sobre funerais e rituais em geral, encontros fúnebres vêm sendo analisados como elementos determinantes na manutenção e renovação dos laços de solidariedade entre as pessoas. Ainda assim, não deixava de chamar a atenção o fato de que o setop, o funeral e a nain nait correspondiam aos poucos, senão aos únicos, encontros nos quais os habitantes de Old Bank esperavam que todos 
(parentes ou conhecidos, amigos e inimigos, residentes ou migrantes, estrangeiros ou locais) estivessem presentes, havendo, sim, uma participação efetiva da maioria da população local.

Ainda outro aspecto, porém, fazia com que esses encontros fossem momentos sociais por excelência. Eles reuniam não somente quem estava visivelmente presente, isto é, os parentes e amigos migrantes, os residentes (nativos ou estrangeiros, aparentados ou não) e também deus, que era uma presença invisível constante, pois era acionado como partícipe nas orações dirigidas a ele, nas letras das músicas cristãs e nos sermões dos pastores. Essas não eram, porém, as únicas presenças invisíveis:

É importante ir aos nain nait para solidarizar-se com a família, porque você se solidarizava com a pessoa quando ela estava viva. É 'nossa tradição' que herdamos das pessoas de antigamente. Alguns dizem que é uma festa para os mortos, outros que é uma festa para celebrar a vida. 'Nossos antepassados' (ui uôlpipl) costumavam dizer que era importante fazer a nain nait, na nona noite, para mandar embora 'o espírito do morto' (di déd spirit). Por isso, nessa última vigília, à meia-noite, eles costumavam bater com um bastão na cama da pessoa que tinha falecido. Caso contrário, seu espírito continuaria voltando para dormir aí, como havia feito durante as noites anteriores. Alguns ainda batem na cama, mas usam um bastão qualquer. Antes usavam um bastão feito com a folha de uma árvore específica. Mas é só 'superstição' (superstición)!

Essas palavras foram pronunciadas por Lôlo, um amigo de aproximadamente 20 anos, em uma entrevista sobre os encontros fúnebres. Ele não tinha o hábito de ir à igreja, algo que fizera na infância, sempre acompanhado pela mãe, que, desde então, já era metodista batizada.

As pessoas de antigamente diziam que nos nain nait tinha muita bruxaria (obeá) e muitos dizem a mesma coisa hoje. Por isso, alguns não gostam (no laik) de ir e participar. Dizem que já viram espíritos ali ou sentiram a presença deles (fíl dem présens). Ficaram com medo (friêd) e sentiram arrepios no corpo todo, a cabeça ficou pesada, doendo... Outros dizem que sonharam com o morto e adoeceram por causa disso... Outros ainda dizem que a doença não foi causada pelo morto e sim por bruxaria ou pelo diabo. Mas eu não acredito nessas coisas, nem deixo de ir aos nain nait de um parente, um amigo ou um vizinho por causa disso. Até porque deus é mais forte que qualquer ameaça. Eu costumo ir sempre e fico no quintal, jogando dominó, ou na sala, cantando.

Embora as opiniões sobre os encontros fúnebres variassem bastante de acordo com a pessoa, Lôlo, Kayra e a maioria dos habitantes de Old Bank descreviam os nain nait como 'importantes', como 'nossa tradição' e não lhes era uma questão relevante saber se se tratavam de festas para os mortos ou para os vivos. Tampouco pareciam preocupados com seu objetivo ou significado - por exemplo, não se interessavam em determinar se os encontros visavam mandar o espírito embora, ou não. Como enfatizavam, porém, algumas pessoas diziam que 'não gostavam' (no laik) de participar dos nain nait.

Muitos vinculavam esse desapreço à ideia de que 'havia muita bruxaria', outros acionavam motivos variados. Uma amiga de 40 anos, que não era batizada e identificava-se como indígena Ngobe, afirmou: "Eu não vou aos nain nait, não gosto dessas coisas. É um desperdício de dinheiro. Participo só do fiuneral, mas não vou à distribuição de comida que fazem depois”. Já outra conhecida, também de 
aproximadamente 40 anos, que se identificava como afro-caribenha e era batizada na Igreja Metodista, afirmava que não ia porque se sentia muito triste, pois se lembrava de todos os entes queridos que perdera ao longo da vida. Ainda outra interlocutora de 20 anos, que se identificava como latina-panamenha e não era batizada em nenhuma igreja, frisou: "Eu não vou ao setop e à nain nait porque 'não gosto' de tresnoitar. Por isso vou só ao funeral'. Por mais críticos que fossem aos nain nait, todos aqueles com os quais pude conversar iam ao menos ao fiuneral e não deixavam de fazer os nain nait quando tinham um morto.

A fala de Lôlo reiterava os aspectos associados à relevância social dos nain nait, evidenciando, não obstante, as 'superstições' em que eles estavam embebidos. Na direção dos apontamentos de Soly citados no início deste texto, a 'superstição' também aparecia como um dos componentes da 'nossa tradição'. Lôlo definiu esse conceito local como aquilo "que herdamos das pessoas de antigamente" (ui acóstium uí inhérit fám fârst táim pipl) e descreveu sua forma de transmissão, a saber, os ensinamentos orais.

Como analisado na relação de Hanna com 'seu velhinho', a comunicação era um dos atos de cuidado que aproximava as pessoas e que criava, matinha e fortalecia os laços de família entre as pessoas. Nesse contexto, era significativo que a comunicação, a qual incluía a transmissão dos ensinamentos orais, tenha sido descrita por meio do verbo 'herdar' (inhérit). Na vila, como em outros lugares, ele se referia justamente ao ato de cuidado realizado por um membro de uma geração ascendente a outro da geração descendente, que recebia daquele objetos de valor econômico, emocional ou prático - como no caso da transferência material das cópias do sanky, herdadas pelas 'irmãs da igreja' de 'seus antepassados' ou, para usar uma tradução mais literal, de 'suas pessoas mais velhas' (ui uôlpipl).

Os ensinamentos herdados evidenciavam outra razão para realizar a nain nait, o nono desses encontros fúnebres: seu objetivo não era somente solidarizar com a família e sim mandar embora o 'espírito do morto'. De fato, durante as nove noites, o espírito, como afirmavam alguns, teria dormido na própria cama e voltaria a fazê-lo no dia seguinte, a menos que fosse realizada a nain nait e que alguém batesse no colchão com um bastão. A descrição desses ensinamentos vinha acompanhada da conjunção adversativa 'mas', do advérbio 'só' e do termo 'superstição', fazendo com que - ao menos para mim soassem como sendo falsos, inválidos ou desvalorizados. No entanto, não deixavam de ser lembrados, valorizados e repetidos, isto é, transmitidos oralmente e praticados.

Esses e outros ensinamentos nos quais os nain nait eram descritos como 'superstição' ou 'nossa tradição' sinalizavam para o fato de que a pessoa recém-falecida se fazia presente, embora seu corpo fosse mantido no necrotério até o dia do funeral. $\mathrm{O}$ falecido era citado nas orações dirigidas a deus e nas conversas sobre sua morte, assim como nas mensagens trocadas pelas pessoas com informações sobre o acontecimento, com manifestações de pêsames etc. Era por causa dele que todos se reuniam nos encontros fúnebres. Nas palavras de Lôlo, "porque você se 'solidarizava' com a pessoa quando ela estava viva”. A seguir, porém, mostrarei que havia uma razão ulterior: era porque o recém-falecido ainda estava ali (ou ao menos podia estar), em 'espírito' (spirit), que as pessoas de antigamente transmitiram os ensinamentos taxados de 'superstição'.

De certa forma, esses ensinamentos pareciam pertencer a uma religião tradicional. Tendo em vista, porém, que isso não era confirmado por meus interlocutores, adotarei uma denominação analítica 
mais neutra, isto é, gestos rituais cotidianos, para me referir a estas práticas: sair dos encontros fúnebres sem se despedir; dar três voltas ao redor do corpo antes de entrar em casa depois desses encontros; caminhar raspando a planta dos pés no chão ao voltar para casa após ter estado no cemitério; manter na casa, durante as nove noites, todos os objetos usados no naint nait e também os pertences do morto; desfazer-se desses objetos no décimo dia.

Entre esses ensinamentos estava a própria realização de um dos encontros fúnebres, precisamente o último deles, em função do qual toda a sequência alcançava a denominação 'os nove noites' - ou 'los nain nait'. Isso sugeria que o nono encontro era, ele próprio, uma 'superstição'. Mais ainda, dava a entender que os nain nait eram, como um todo, uma 'superstição'. A necessidade de lembrar e repetir, oralmente ou na prática, todos os ensinamentos taxados de 'superstição' atestava, por um lado, a presença do espírito da pessoa recém-falecida e, por outro, dava a entender que esta era perigosa. $\mathrm{O}$ interessante é que os espíritos em geral eram igualmente vistos como estando presentes e sendo perigosos - isto é, o espírito de qualquer morto e não somente o do homenageado nos nain nait era enquadrado nessa situação. Semelhantemente, eram citados como presentes e perigosos a bruxaria e o diabo.

Embora os espíritos dos mortos fossem invisíveis para mim e para a maioria de meus interlocutores, algumas pessoas afirmavam que os viam ou 'sentiam sua presença' (fil dem présens). Segundo elas, tal presença podia ser captada por meio da visão, do tato e de outros estímulos externos e internos ao corpo. Ela, conforme Lôlo me dissera, causava medo, arrepios no corpo todo, dor e sensação de peso na cabeça, sonhos e doenças. Estas últimas, por sua vez, eram descritas como sendo causadas também pelo diabo e pela bruxaria mandada por alguém.

O diabo se fazia presente por meio das constantes menções que lhe eram feitas em falas como as de Lôlo ou em expressões como 'não é possível viver com deus e com o diabo'. Já frases como 'aqui em Old Bank tem muita bruxaria' ou 'nos nain nait, tinha muita bruxaria' ensinavam e atestavam a existência da bruxaria e, por extensão, de pessoas que a praticavam - isto é, os bruxos (obeamán). Portanto, o diabo, a bruxaria e os espíritos dos mortos se faziam tão presentes nos nain nait quanto as pessoas ausentes ou deus. Todas essas presenças, quase sempre invisíveis, eram constantemente acionadas como partícipes dos nain nait, assim como as pessoas que estavam visivelmente presentes. No entanto, a presença da bruxaria, dos espíritos dos mortos e do diabo aparecia como algo perigoso e, por isso, devia ser afastado por meio da atualização dos ensinamentos.

Como herança, a transmissão dos ensinamentos taxados de 'superstições' era feita como um gesto familiar cotidiano. Era um dos atos de cuidado englobados no 'viver como família', isto é, criavam, mantinham e fortaleciam os laços que caracterizavam a família. Considerado isso, pode-se dizer que esses ensinamentos pertenciam ao âmbito das relações com os parentes, tal como os demais gestos familiares cotidianos. A atualização desses ensinamentos também correspondia a um ato de cuidado, no qual estavam incluídos os nain nait e os gestos rituais cotidianos supracitados. Entretanto, em vez de aproximar, criando, mantendo e fortalecendo vínculos (como os atos de cuidado do viver como família'), a concretização das 'superstições' realizava um movimento diferente, pois protegia e afastava os vivos da perigosa presença (invisível) dos espíritos dos mortos, da bruxaria e do diabo. Por essa razão, denominarei a atualização das 'superstições' de práticas de afastamento, chamando, assim, a atenção 
para o fato de que as 'superstições' e os nain nait eram, simultaneamente, práticas de aproximação entre as pessoas e práticas de afastamento em relação a perigos.

\section{“Todos acreditamos em deus, mas"}

Nossos avós sempre contavam histórias sobre pessoas que viam espíritos e fantasmas, como o Homem sem Cabeça (Chapapmán), o Homem Negro (Blakmán), a Chorona (Llorona). Eles vagam aqui por Old Bank e viveram muito tempo atrás, antes da chegada de Miss Abi, quando aqui era um cemitério. Quem pode ver espíritos realmente os vê. Dizem que as pessoas podem vê-los quando nascem com o 'véu' (velo/ cál), cobrindo o rosto. Espíritos e fantasmas existem, porque existe o mal, o diabo existe! E existem anjos maus ligados a ele. O diabo e esses anjos maus podem adotar a aparência de pessoas que morreram para enganar os vivos. Fazem isso porque quem acredita em bruxaria acha que são espíritos mandados por um bruxo, e aí também procuram um bruxo para combater essa bruxaria! Só que fazer isso é combater o mal com o mal, o que causa mais mal! Só podemos combater o mal com o bem, com deus!

Ao recolher histórias como esta acima, percebi como todas as práticas de afastamento haviam sido herdadas de duas maneiras: oralmente, por meio da transmissão de ensinamentos e também materialmente, por meio da transferência das mesmas cópias da Bíblia que haviam sido levadas à ilha de Bastimentos pelos antepassados fundadores. Essas duas modalidades de heranças ecoavam outras que eu já conhecia: a transferência (material) das cópias do sanky, que também haviam sido levadas à ilha pelos antepassados fundadores e ainda a transmissão (oral) de ensinamentos sobre a história da chegada a Bastimentos dos antepassados e também sobre a passagem dos missionários metodistas e adventistas por ali.

Narrativas orais sobre a história da vila, dos bairros e da genealogia individual transmitiam o conhecimento sobre uma herança compartilhada pela população de Old Bank. De fato, todos descendiam dos mesmos cinco antepassados fundadores, os quais haviam estabelecido casamentos entre si, fazendo com que 'todos fossem família' (dé al fámili), ainda que 'nem todos vivessem como família' (no al a ui liv láik fámili). Tais narrativas enfatizavam que esses antepassados eram negros livres que vinham do Caribe e haviam chegado à ilha de Bastimentos nos séculos XIX e XX. O que as narrativas deixavam implícito, contudo, era que esses antepassados haviam viajado no mesmo período que uma missionária afro-caribenha estabeleceu ali a igreja metodista (precisamente em 1814) e que missionários instauraram a igreja adventista (em 1909), passando pelos mesmos caminhos, desde o Caribe até a ilha, de onde seguiram para o restante do arquipélago de Bocas del Toro e para a América Central. Portanto, ainda que ninguém reconhecesse os missionários como parentes e que, inversamente, os antepassados fundadores não fossem necessariamente descritos como cristãos (ou como pessoas convertidas ao cristianismo pelos missionários), a herança deixada por todos eles era a mesma. E essa herança era precisamente o que meus interlocutores denominavam de 'nossa tradição': (i) os gestos cristãos cotidianos (as práticas de afastamento indireto, mediadas por uma aproximação a deus); (ii) os gestos rituais 
cotidianos (as práticas de afastamento direto, taxadas de 'superstição', entre as quais estavam incluídos os nain nait); (iii) os gestos familiares cotidianos (as práticas de aproximação às pessoas).

A população de Old Bank aprendia sobre o conceito de 'nossa tradição' por meio da herança (não somente oral, mas também material) recebida, seja dos antepassados fundadores, seja dos missionários cristãos. Todas essas 'pessoas de antigamente' (fârst taim pipl) haviam, pois, 'vivido como família' com eles ao concretizar um dos atos de cuidado que criavam, mantinham e fortaleciam laços característicos da família. Em especial no caso da missionária metodista, ela tinha deixado como herança as cópias materiais da Bíblia e dos hinários cristãos - todos em inglês e impressos no império britânico no século XIX -, os quais ainda eram usados nos cultos.

Por sua vez, os antepassados familiares transferiram a herança das cópias (também em inglês e impressas no império britânico no fim do século XIX) da Bíblia e do sanky trazidos do Caribe ao chegar à ilha de Bastimentos. A herança material deixada pelos antepassados familiares sugeria que eles já dispunham do conhecimento englobado no conceito de 'superstição' associado aos nain nait, o qual era indissociável do conhecimento sobre o cristianismo. Somada à herança material da terra familiar, os antepassados fundadores transmitiram, por meio dos laços de família criados de geração em geração, os ensinamentos sobre os gestos cristãos cotidianos, sobre os gestos rituais cotidianos e sobre os gestos familiares cotidianos.

Desde o início da história de Old Bank, já se entrelaçavam os conhecimentos sobre família e bruxaria, sobre deus e diabo, nain nait e espíritos dos mortos, os quais eram atualizados nos gestos familiares, nos gestos cristãos e nos gestos rituais cotidianos. Todos foram trazidos, seja por missionários (inclusive uma mulher afro-caribenha), seja pelos antepassados fundadores (homens e mulheres afro-caribenhos). Todos foram herdados por meio de objetos materiais (cópias da Bíblia e do sanky) e também por meio de narrativas orais. Todos, por fim, eram referidos, no presente, como 'nossa tradição'. Nenhum deles era, portanto, mais nativo ou estrangeiro, puro ou misturado, autêntico ou aculturado que o outro. Tratava-se de conhecimentos diferentes que não estavam separados - leia-se, não estavam restritos ao domínio do parentesco, nem ao domínio da religião. Estavam, sim, incorporados na temporalidade e espacialidade de Old Bank, por meio da transmissão de ensinamentos orais e da transferência de objetos materiais. Ademais, estavam literalmente incorporados nas pessoas.

\section{6. "Todos somos família, mas..."}

Todos nós somos criaturas de deus, por isso ele é nosso pai sagrado (buoli fadá). Ele criou Adão e Eva, que são os nossos primeiros pais, nosso primeiro pai e nossa primeira mãe (ui fârst fáda an máda). Todos nós descendemos deles, você, eu, todos! Nós pertencemos a deus do mesmo jeito que pertencemos a nossos pais. E estamos combinados (combáin) com nossos pais do mesmo jeito que estamos combinados com deus, nosso pai 'todo poderoso' (olmáiti). Nós somos filhos dele do mesmo jeito que somos filhos dos nossos pais. O sangue dos nossos pais está no nosso cor- 
po (bádi), assim como o Espírito Santo (Huôli Guôst), que é o espírito de deus. Mas os espíritos maus ${ }^{11}$ (bádspirit), que estão ligados ao diabo e aos anjos maus, eles também estão no nosso corpo.

Surpresa ao ouvir essas palavras de minha professora do idioma local, quis ratificar: "O Espírito Santo e os espíritos maus estão no nosso corpo?":

Sim. Esses dois tipos de espíritos estão sempre no nosso coração e na nossa mente, conversando (tág) com a gente. Você tem o seu espírito criado por deus, sua alma (suol), que é quem decide, mas também escuta essas duas vozes. Você sabe do que estou falando, você também os escuta quando fica na dúvida entre o que fazer, sabe? Todos já passamos por isso! Você escuta, na sua mente ou no seu coração, como se fosse uma voz dentro de você que te sugere a coisa certa a fazer, enquanto tem outra voz que te estimula a fazer a coisa errada.

Soly seguiu explanando:

Os espíritos maus, a morte, o pecado, penetraram no corpo (bádi) dos nossos primeiros pais. Nós herdamos isso de Adão e Eva, do mesmo jeito que herdamos deles o nosso corpo, com tudo o que tem nele: carne, osso, sangue e também o Espírito Santo e os espíritos maus. Por causa do pecado dos dois, todos nós estamos em pecado, porque deus pode até nos perdoar pelos nossos pecados, mas as consequências de cada pecado passam de geração em geração. Assim, nós herdamos as consequências do pecado dos nossos primeiros pais, Adão e Eva, do mesmo jeito que herdamos os pecados que nossos pais e avós cometeram. Essas consequências são a doença, a morte, a velhice, todos os problemas que você pode ter. É por isso que as crianças começam a fazer coisas más assim que deixam de ser bebês. Está na nossa natureza como descendentes de Adão e Eva, recebemos deles essa herança.

Segundo Soly e outros interlocutores, cada ser humano recebia duas heranças essenciais de seus ancestrais (paternos e maternos): o sangue humano e um conjunto de espíritos, isto é, o espírito individual (alma), o espírito bom (chamado Espírito Santo) e o espírito mau (sem denominação própria). O sangue humano era descrito como uma substância vital material que fazia o corpo (bádi), enquanto os espíritos eram capacidades vitais essenciais que animavam o corpo, fazendo dele um ser vivo pensante e actante. Tais espíritos residiam dentro do corpo (especificamente na mente e no coração) e eram experienciados regularmente por todo ser humano como duas vozes que lhe sugeriam o que fazer.

Ao frisar que todos os seres humanos descendiam de Adão e Eva e haviam sido criados por deus, meus interlocutores indicavam que todos estávamos aparentados. Isso não significava, porém, que agrupassem a humanidade em um coletivo familiar. Aprendi então como o que fazia o parentesco era diferente do que fazia a família. Esta era construída por meio da atualização dos gestos familiares cotidianos, ou seja, dos atos de cuidado englobados no 'viver como família', os quais eram determinantes

11 Chamo a atenção para o adjetivo mau (bád), cujo uso mais comum não era qualificar os espíritos, mas sim a população de Old Bank e o idioma local. Ele era frequentemente utilizado junto (ou como alternativa a) o adjetivo ráf, podendo ambos ser traduzidos como mau/ duro/errado/grosseiro/forte, por exemplo, nas seguintes formulações: "algumas pessoas aqui falam um guari-guari bem raf", "aqui as pessoas crescem raf", "as pessoas aqui são bád". 
para a aproximação entre as pessoas e para a criação, a manutenção e o fortalecimento dos laços que caracterizavam a família. Por outro lado, o parentesco dizia respeito às relações dadas. Entre deus e os seres humanos (vivos e mortos), o parentesco (bíblico) fora estabelecido pelo ato inicial de criação. Decorrente disso, está o fato de que, embora meus interlocutores não o reconhecessem explicitamente, havia um parentesco (bíblico) também entre os seres humanos, o diabo e seus anjos maus - posto que todos eram criaturas divinas. Por outro lado, no que dizia respeito aos laços de família entre os seres humanos vivos e mortos, eles eram instaurados no ato do nascimento e envolviam a partilha do mesmo tipo de sangue (humano) e dos mesmos tipos de espírito - o Espírito Santo, associado a deus e os espíritos maus, vinculados ao diabo e aos anjos maus. Principalmente, porém, esses laços eram mantidos ou enfraquecidos, fortalecidos ou rompidos ao 'viver como família', ou não.

Em Old Bank, duas pessoas eram descritas como ‘sendo família’ quando cada uma sabia que partilhava ao menos um antepassado comum. Entretanto, tal conhecimento não se limitava aos antepassados caribenhos (fundadores das famílias locais), ele abarcava também os antepassados bíblicos, Adão e Eva (os 'primeiros pais' humanos) e deus (o 'pai sagrado', ser não-humano que criou a humanidade). Portanto, havia uma razão ulterior para que os habitantes de Old Bank dissessem "somos família”, afirmando assim seu parentesco no sentido de 'mutualidade do ser' (Sahlins 2011a; 2011b): eles sabiam que partilhavam o sangue dos mesmos antepassados bíblicos, além dos mesmos antepassados caribenhos.

Entretanto, quando meus interlocutores sublinhavam que "nem todos somos família", eles chamavam a atenção para uma diferença entre aquilo que instituía o parentesco, leia-se, o 'todos somos família', e aquilo que fazia a família, entendida como vínculos construídos por meio do 'viver como família. Tal construção era realizada por meio dos atos de cuidado englobados no 'viver como família', os quais criavam, mantinham e fortaleciam os laços de família. E essa construção não se limitava aos seres humanos: ela se estendia a deus. De fato, os atos de cuidado englobados no 'viver como família' eram determinantes para a aproximação, seja entre os seres humanos, seja entre eles e deus.

Com base no material etnográfico apresentado neste texto, parece-me possível argumentar que, em Old Bank, não se pode traçar uma fronteira entre parentesco e religião. De fato, as práticas e ideias locais de relatedness (Carsten 2000) focavam, não em pertencimentos exclusivos relativos ao sangue e ao sobrenome (no caso da família) ou à filiação a uma doutrina cristã específica (no caso da religião), mas sim ao liv laik fámili. Durante os ritos extraordinários dos nain nait e os demais atos de cuidado cotidianos - entre os quais inexistiam fronteiras - a ênfase recaía sempre sobre o 'viver como família' junto com agências não/humanas e i/materiais: pessoas vivas e mortas, deus, diabo, bruxos. A coexistência entre elas foi herdada pelos habitantes de Old Bank dos próprios antepassados afro-caribenhos e dos próprios parentes Bíblicos, sendo que dois deles literalmente habitavam os corpos das pessoas por meio de seus espíritos - o Espírito Santo e os espíritos maus, ligados respectivamente a deus e ao diabo, isto é, ao pai e ao irmão da humanidade bíblica.

\section{Claudia Fioretti Bongianino é doutora em Antropologia Social pelo Museu Nacional/UFRJ.}




\section{REFERÊNCIAS BIBLIOGRÁFICAS}

ACETO, Michael. 1995a. "Variation in a secret creole language of Panama." Language in Society, 24(4): 537-560.

. 1995b. "Syntactic innovation in a Caribbean creole: The Bastimentos variety of Panamanian Creole English". English World-Wide, 17: 43-61.

1996. Variation in a variety of Panamanian Creole English. Tese (Doutorado em Linguística) - Universidade de Texas, Austin.

. 1998. “A new creole future tense marker emerges in the Panamanian West Indies." American Speech, 73(1): 29-43.

BESSON, Jean. 1984. "Family land and Caribbean society: Toward an ethnography of Afro-Caribbean peasantries." In: THOMAS-HOPE, Elizabeth M. (Org.). Perspectives on Caribbean Regional Identity, Liverpool (RU): Center for Latin American Studies, University of Liverpool. p. 57-83.

.2002. Martha Brae's Two Histories: European Expansion and Caribbean Culture-Building in Jamaica. Chapel Hill: University of North Carolina Press.

BONGIANINO, Claudia Fioretti. 2012. Malas de sonhos e saudades: familia e mobilidade entre cabo-verdianos na Itália. Dissertação (Mestrado em Antropologia Social), Universidade de Brasília, Brasília.

. 2014. "Tornar-se afro-caribenho. Ensaio bibliográfico sobre família e mobilidade no Caribe”. Revista Teoria e Cultura, Juiz de Fora, 9: 63-76.

.2015. "Crescendo pessoas, relações e lugares: experiências cabo-verdianas sobre família e mobilidade". Cadernos Pagu, 45: 111-133.

2018. Deus e outros parentes invisiveis em Old Bank (Bocas del Toro, Panamá). Tese (Doutorado em Antropologia Social). Museu Nacional, Universidade Federal do Rio de Janeiro, Rio de Janeiro.

BRERETON, Leticia C. Thomas. An exploration of Panamanian Creole English: Some syntactic, lexical and sociolinguistic features. Tese (Doutorado em Linguística) - University of New York, New York (EUA), 1992.

CARNEGIE, Charles. 1987. "Afro-Caribbean villages in historical perspective”. African-Caribbean Institute of Jamaica 2: 123-157.

CARSTEN, Janet. 2000. “Introduction”. In: (Org.) Cultures of Relatedness: new approaches to the study of kinship. Edinburgh (RU): CambridgeUniversity Press.

CLARKE, Edith. 1999 [1957]. My Mother Who Fathered Me: A study of the families in three selected communities of Jamaica. Mona (Jamaica): University of West Indies Press.

CRICHLOW, Michaeline. 1994. "An alternative approach to family land tenure in the Anglophone Caribbean: The case of St. Lucia”. New West Indian Guide 68(1/2): 77-99.

DURKHEIM, Emile. 1989. The Elementary Forms of Religious Life. New York: Free Press.

FABIAN, Johannes. 1973. "How others die - reflections on the anthropology of death." Social Research 39(3): 543-567.

HERTZ, Robert. 2003 [1907]. «Contribution à une étude sur la représentation collective de la 
mort.» L'Année sociologique 1896/1897-1924/1925 (10): 48-137.

INEC, Instituto Nacional de Estadistica y Censo. 2009-2010. Census and Cartography. Ciudad de Panamá.

JUSTAVINO, Nilsa. 2010. Reflexiones sobre el ingles panameño. Correo enviado a Ines Sealey, 29 jun. 2010. Editado para el Internet: Anthony McLean H. 2010. Disponível em: <http://diadelaetnia. homestead.com/InglesPanama.html>. Acesso em: 03 abr. 2017.

. 1975. West Indian English dialects in Panama: A historical, social and linguistic approach to West English dialects in Panama. Ciudad de Panamá (Panamá): Universidad de Panamá.

MAUSS, Marcel. 2012. «Effet physique chez l'individu de l'idée de mort suggérée par la collectivité. > Journal de Psychologie Normale et Pathologique, 311-330.

MINTZ, Sidney W. 1974. «Houses and Yards among Caribbean Peasantries,». IN: (Org.).

Caribbean Transformations. New York (EUA): Columbia University Press: 225-50.

MUEHLEISEN, Susanne; MIGGE, Bettina (Orgs). 2005. Politeness and face in Caribbean Creoles. Amsterdam (Holanda): John Benjamins Publishing.

OLWIG, Karen Fog. 1999. “Caribbean place identity: From family land to region and beyond”. Identities Global Studies in Culture and Power 5(4): 435-467.

2007. Caribbean journeys: an ethnography of migration and home in three family networks.

Durham (EUA): Duke University Press Books.

REID, Heidi. 2013. Bastimentos Creole English, Bocas del Toro, Panama. Disponível em: <https:// heidireidmanchester.wordpress.com/extra/>. Acesso em: 04 mar. 2017.

SAHLINS, Marchall. 2011a. "What kinship is" (part one). Journal of the Royal Anthropological Institute 17(1): 2-19.

.2011b. "What kinship is" (part two). Journal of the Royal Anthropological Institute 17(2):

242, 2011

SCHNEIDER, Edgar Werner \& KORTMANN, Bernd (Orgs.). A handbook of varieties of English: a multimedia reference tool, v. 1. Berlin (Alemanha): Walter de Gruyter, 2004.

SMITH, Raymond T. 1956. The negro family in British Guiana. Family Structure and social status in the villages. London: Routledge \& Kegan Paul Limited.

SNOW, Peter. 2000. "The case for diglossia on the Panamanian island of Bastimentos." Journal of Pidgin and Creole languages, 15(1): 165-169.

.2001. "A discrete co-systems approach to language variation on the Panamanian island of

Bastimentos". University of Pennsylvania Working Papers in Linguistics 7 (3): 20-53.

.2003. "Talking with tourists in a Panamanian creole village: An Emerging site of production." Journal of Pidgin and Creole languages, 18(2): 299-309.

2004. What happen: Language socialization and language persistence in a Panamanian Creo-

le village. Tese (Doutorado em Linguística) - Universidade da Califórnia, Berkeley.

. 2005. "The use of bad language as a politeness strategy in a Panamanian Creole village". In:

MIGGE, B.; MÜHLEISEN, S. (Orgs.). Politeness and Face in Caribbean Creoles. Amsterdam (Holanda): John Benjamins, 51-83. 
2007. "Vernacular shift: Language and the built environment in Bastimentos, Panama." Identities: Global Studies in Culture and Power, 14(1-): 161-182. SPRAGG, Marva Myles. 1973. Origin and nature of the English dialect of Colon and its implications for the teaching of standard English. Ciudad de Panamá (Panamá): Universidad de Panamá, 1973. TROUILLOT, Michel-Rolph. 1992. “The Caribbean Region: an open frontier in anthropological theory." Annual Review of Anthropology 21:19-42.

TURNER, Victor. 1969. The Ritual Process. London: Routledge and Kegan Paul.

VAN GENNEP, Arnold. 1960 [1909]. The Rites of Passage. London (RU): Routledge. 


\section{FRONTEIRA MATERIAIS E ESPIRITUAIS: EXIBINDO A COEXISTÊNCIA ENTRE deus e outros parentes afro-caribenhos em Old Bank, Panamá}

Resumo: A análise se inspira em uma exibição museológica sobre as tradições fúnebres da vila afro-panamenha de Old Bank (localmente chamadas de "nain nait"), a qual foi projetada por meus interlocutores e por mim em 2016. Com base nessa experiência e em quinze meses de etnografia, argumento que é impossível traçar uma fronteira entre parentesco e religião ali. De fato, as práticas e ideias locais de relatedness focam, não em pertencimentos exclusivos relativos ao sangue e ao sobrenome (no caso do parentesco) ou à filiação a uma doutrina específica (no caso da religião), mas sim na atualização de ritos extraordinários e atos de cuidado ordinários resumidos como "liv laik fámili". Isto é, focam no "viver como família" junto com agências não/humanas e i/materiais, cuja coexistência foi herdada dos próprios antepassados afro-caribenhos e dos próprios parentes Bíblicos (entre os quais, Deus e Diabo), que literalmente habitam os corpos das pessoas.

Palavras-Chave: Parentesco; Religião Funerais; Cotidiano; Afro-caribenhos.

\section{MATERIAL AND SPIRITUAL BORDERS: EXHIBITING COEXISTENCE BETWEEN god and other Afro-Caribbean relatives in Old Bank, Panama}

Abstract: Inspired by a museum exhibition about the funerary tradition (called "nain nait"), designed in collaboration by the dwellers of the Afro-Panamanian village of Old Bank and myself, I use my fifteen months of ethnographic fieldwork to argue that it is impossible to separate religion from kinship there. In fact, local practices and ideas of relatedness do not focus on exclusive blood or last name rules of belonging (in the case of kinship), nor on rigid affiliations to a specific Christian doctrine (in the case of religion). Instead, they focus on the enactment of extraordinary rites and ordinary acts summarized as "liv laik fámili". In other words, the dwellers focus on the "living like family" with non/human and $\mathrm{im} /$ material agencies, and on two known facts: the coexistence among such agencies was inherited from their own Biblical relatives (as God and the Devil); and such agencies literally inhabit people's bodies.

Keywords: Kinship; Religion; Daily Life; Afro-Caribbean.

RECEBIDO: $17 / 02 / 2019$

APROVADO: 23/06/2019 